\title{
On the Optimization of Sentence Imitation in Primary School English Teaching from the Perspective of Strong Memes
}

\author{
Wang $\operatorname{Lin}^{1,2}$ \\ ${ }^{1}$ School of Foreign Languages and Literature, Wuhan University, Wuhan, China; \\ ${ }^{2}$ School of Foreign Languages, Leshan Normal University, Leshan, China \\ Correspondence: Wang Lin, School of Foreign Languages and Literature, Wuhan University, Wuhan, China; \\ School of Foreign Languages, Leshan Normal University, Leshan, China. Tel: 138-8048-4919. E-mail: \\ w_lin832@163.com
}

Received: March 3, 2017 Accepted: April 1, 2017 Online Published: April 4, 2017

doi: 10.5539/elt.v10n5p11 URL: http://doi.org/10.5539/elt.v10n5p11

\begin{abstract}
A sentence is an important unit in English language, and plays a crucial role in language teaching and learning as well. For many years, sentence teaching is always worth discussion in English teaching, because sentence imitation is very important for students' construction of logical discourse. This paper, based on memetics, proposes some certain optimization strategies of sentence imitation in primary school English teaching from the perspective of strong memes, and points out that efficient sentence imitation is of great importance in primary school English teaching.
\end{abstract}

Keywords: optimization of sentence imitation, English teaching, primary school, strong memes

\section{Introduction}

At present, English has been taught as a formal course in most primary schools in China, and sentence teaching is undoubtedly an important procedure in English teaching. According to Compulsory Education English Curriculum Standards (2011 edition) by The Ministry of Education of The People's Republic of China, primary school students should write short sentences with the help of pictures, phrases or model sentences (2012). Hence it can be easily seen that sentence writing is both an essential ability for primary school students and a requirement stipulated by Curriculum Standards. For primary school students, sentence writing must begin with sentence imitation of existing good model sentences. But how to define the models for imitation is a big question for both teachers and students, since it closely relates to the effect of sentence imitation and writing. Thus, how to optimize sentence imitation is of great importance and necessity.

\section{Current Situation of Writing Teaching in Primary School}

English teaching generally begins in Grade Three in the primary school in China. According to the author's survey on the teaching of English writing in some primary schools nearby in a certain district, there are some problems as following.

Firstly, composition writing training begins relatively late. Most students below Grade Six cannot independently write a complete short composition. Specifically speaking, most students in Grade Four and Grade Five only write a simple sentence or make a reply sentence to a question with the supervision of their teachers or with the help of their textbooks.

Secondly, model sentences for imitation or training are insufficient in characteristic induction and category summary. Some teachers are likely to confine the model sentences to those in textbooks only or to provide model sentences at random without prominent characteristics for summary, so it is difficult for beginner students to draw inferences by themselves and to make analogous sentences as many as possible. Thus students can hardly form a systematic structure map in their minds.

Thirdly, some students are quite lacking in graveness and chariness in imitation and writing, which is partially due to lack of their teacher's supervision and their sluggishness. Most students can perfectly finish sentence transcription, sentence imitation or sentence making in class with the teacher's guide and supervision. However, on the contrary, a quite number of students make mistakes of spelling, structure or grammar when they write 
independently at home. In fact, to a large extent, students' lack of graveness and chariness is due to their lack of interest in and consolidation of model sentences.

\section{Literature Review}

In view of the feature of replicability, the meme has been brought into language research a few years before. In recent years with the introduction of memetics into language teaching, there are a few scholars having done research on sentence imitation from the perspective of memetics. Some scholars studied writing and sentence imitation in college English teaching from the perspective of memetics and proposed certain strategies (Wu, 2007; Shen \& Deng, 2013; Ma, 2014), and some scholars studied writing and sentence imitation in vocational college English teaching from the perspective memetics and proposed certain strategies (Zhang, 2012; Xi, 2014). However, there are very few scholars having involved with English sentence imitation in primary school stage through memetics. According to the author's search, there is only one paper about English writing and sentence imitation in primary school (Chen \& Zhou, 2015), but it is done from the perspective of process-oriented writing. According to the author, meme's feature of replicability matches sentence imitation very well. Therefore, in other words, it is very feasible and significant to study sentence imitation in English teaching at the stage of primary school - the golden age of language learning.

\section{Meme and Strong Meme}

The concept of "meme" comes from sociobiology, where it was introduced by the British biologist Dawkins in The Selfish Gene (1976) (Chesterman, 2012). According to Chesterman, a meme is a unit of cultural transmission, or a unit of imitation (2012). A meme must go through such procedures as duplication, transformation and selection. In other words, any unit that can be imitated, duplicated and transmitted can be named a meme such as music, idea, catchword, dress, fashion and internet. Generally speaking, a meme develops through the following four stages - 1) assimilation(In this stage, the successful meme can affect its host and goes into the host's memory.), 2) retention (In this stage, the meme can be kept in the host's memory, and the time of a meme kept in the host's memory is a key element.), 3) expression (In this stage, a meme should transform into the tangible form from the memory) and 4) transmission(In this stage, the tangible carrier or medium is needed for further transmission of the meme) (He, Xie, \& Chen, 2007). Furthermore, any stage mentioned above can directly affect the transmission of a meme. Additionally, in the process of transformation and transmission, a meme can be either strong or weak according to the variety of situation. The strong meme is superior to the weak one in many aspects such as vitality, the degree of fidelity, transmission speed, transmission effect and so on. As Dawkins (1976) put, the strong meme is of the three features - copying-fidelity, fecundity and longevity. In general, it is easy to conclude that strong memes are stronger in vitality and more successful in cultural transmission than the weak ones. Therefore, the three features of strong memes are important and inspiring for the optimization of meme transmission.

As an important tool for human communication and transmission, the language is definitely a kind of meme. The principle of language acquisition is similar to the principle of meme transmission - second language input (imitation and assimilation of a meme) $\rightarrow$ overt and covert knowledge (retention and expression of a meme) $\rightarrow$ second language output (transmission of a meme). Therefore, it is feasible to teach language by means of the principle of meme transmission, and it is certainly the same case with English teaching in the primary school since the rules of imitation and assimilation can well matches the primary school students who learn English as beginners. As the beginners for English acquisition, primary school students may not own perfect subjective initiative for English learning. Therefore, interest stimulation and memory intensification are quite important especially at the fundamental stage, which can be well solved by appropriate application of strong language memes. In summary, the sentence imitation and writing in the primary school can be effectively improved on condition that teachers can effectively introduce strong memes into the teaching and training of English writing.

\section{Sentence Imitation through the Three Features of Strong Memes}

\subsection{Copying-fidelity and Sentence Imitation}

The feature of copying-fidelity of memes means that memes are likely to keep their original essence instead of being changeless in the process of copying (He et al., 2007). In other words, copying-fidelity indicates the extent on which the memes after copying conform to the original forms before copying. On one hand, if the memes after copying can highly conform to those before copying in terms of information preservation, these memes are of high copying-fidelity. Therefore, with powerful vitality, they can easily assimilate the hosts (primary school students) and enter the hosts' memory, basically realizing the successful transformation. On the other hand, if the memes after copying can poorly conform to those before copying in terms of information preservation, these memes are of low copying-fidelity, thus they are very likely to alter or lose information and even die out. In view 
of this, the teacher can consciously select those sentence memes with high copying-fidelity and bring them to writing teaching and training.

For example, "too...to" structure is a frequently used structure in English, indicating that there is a greater amount or degree of something than is desirable, necessary or acceptable so that something cannot be realized or done. Therefore, the relatively fixed meaning of "too...to" structure makes it easy for primary school students to acquire and master. According to the strong meme of "too...to" structure and model sentence, students can imitate a group of sentences such as "I am too busy to help you", "He is too short to see the screen", "They are too young to understand the story" and "The hat is too large to wear". What's more, the teacher can introduce "so...that" structure to students and encourage them to do imitation practice and pattern conversion.

Another example is "...would like..." structure, which is also frequently used in English indicating a wish or a desire for something or to do something, and is also a meme of high copying-fidelity. Based on it, students can be encourage to make many sentences such as "I would like a cup of tea", "He would like an apple", "Would you like a piece of bread", "We would like to go out for a picnic" and "We'd like to ride around the lake". Students can make various sentences according to their various situations and thoughts, thus interests and initiative can be greatly enhanced. In this way, students not only get the structure grammatically, but also improve and expand their writings.

Actually, there are a lot of structures with high copying-fidelity, which are frequently used in primary school English and quite available for conversion and expansion. If the teacher can induce and introduce sentence memes of high copying-fidelity to students, the difficulty of sentence imitation and writing can be greatly reduced and the interest of students can be strengthened to achieve a better effect.

\subsection{Fecundity and Sentence Imitation}

Fecundity is very important for memes. According to He et al. (2007), the distinction among genes lies in their respective effects on embryo development, body configuration and behaviors, thus the successful genes are those that can exert beneficial effects on embryos. Similarly, the sentence memes with high fecundity also have beneficial effects, that is, to produce more replicas (A core sentence pattern, which is a strong meme, can produce more collocation structures), which is of great significance for the successful transmission of the original meme. In teaching, the teacher should pay special attention to the sentence memes with high fecundity.

For example, "What is your name" is a frequently used question and also a model sentence with high fecundity. The teacher can make full use of this model sentence to lead students to imitate more. There are mainly three steps.

Step 1

What is your name? $\rightarrow$ What is his name? $\rightarrow$ What is her name? $\rightarrow$ What is someone's name?

Step 2

What is your habit? $\rightarrow$ What is his hobby? $\rightarrow$ What is her phone number? $\rightarrow$ What is someone's sth?

Step 3

What is your favorite color? $\rightarrow$ What is his favorite animal? $\rightarrow$ What is someone's+adj+sth? $\cdots$

In Step 1, students are encouraged to make sentences closely relating to the model asking other's name. In Step 2, students are encouraged to make sentences that are based on the model but relate to other aspects in the daily life of other people. In Step 3, students go on with the basic structure but they can add some other modifiers to enrich their sentences.

From the example above, it is easy to see that students can make a lot of sentences through imitating the model sentence "What is your name". In this way, their minds and writings can be enriched and improved.

Similarly, typical dialogues are also of high fecundity, so that they can also be taken as strong memes for sentence imitation and writing. For example, there is a practice in Module 2 Unit 1 from the English textbook for Grade Five (Chen, 2014, p. 10). According to this practice, students are required to write reply sentences on the basis of a model dialogue (A: Did she make a cake yesterday? B: No, she didn't.) and four pictures(cooking, watching TV, working and walking).In fact, this dialogue is a typical model dialogue, which is frequently used in a certain period of time. Therefore, besides reply training, the teacher can ask students to imitate new dialogues according to the model dialogue. For example, new dialogues can be produced as following, 
B: No, she didn't.

2) A: Did he play football yesterday afternoon?

B: No, he didn't.

3) A: Did they go to cinema last night?

B: No, they didn't.

4) A: Will you come to my house tomorrow morning?

B: Yes, I will.

From the four examples listed above, imitation is quite effective. In the first example, students imitate the model structure but modify the object. In the second example, students imitate the model structure but modify the subject and the predicate. In the third example, students imitate the model structure but modify the subject, the predicate and the adverbial of time. In the fourth example, students imitate the model structure but modify the subject, the predicate, the adverbial of time and the tense. In fact, students can keep making different sentences according to the model. In other words, one hundred students can make one hundred different sentences that are within the structure of model sentence. Naturally, students' writing can be greatly improved and their thinking can be greatly expanded in this way.

What' more, typical paragraphs are also of high fecundity. There is a case from the English textbook for Grade Six (Chen, 2014, p. 37). The modal paragraph is "My name is Lulu. I'm Chinese. This is my friend Anne. She is American. I use chopsticks, but Anne..." Similar to dialogue-making, students can write various paragraphs about their respective situation based on the model. They can write something about name, age, nationality, hobby, telephone number, address, family members, hometown, ideal in the future and other information. Sentence imitation can pave the way for paragraph writing and even passage writing.

Therefore, it can be concluded that if the teacher can focus on sentence memes with high fecundity, he/she can effectively push students to improve their writing ability.

\subsection{Longevity and Sentence Imitation}

The feature of longevity means that a meme can be preserved in a meme pool for a very long period of time, and that is to say a meme can be kept on paper or in people's mind for a very long time (He et al., 2007). It is the feature of longevity that makes strong memes can be kept in people's mind for so long time. For example, the phrase "-gate" is a strong meme with powerful longevity indicating scandal or crisis after it was firstly used in "Watergate Scandal". Thus, here come a lot of "-gate" phrases like "Intelligence Gate" and "Irangate".

Similarly, the teacher should select some sentence memes with powerful longevity as model sentence, and bring them for students' training. For example, when the teacher introduces a nice song named I believe I can fly to students, he/she can make the name a model for students' training since the name has been kept in people's mind for long. Probably, students can imitate the model and make some other sentences such as "I believe I can succeed", "I believe I can win", "I believe I can cook", "I believe I can jump high" and "We believe we can deal with it". The name of another classical English song My heart will go on is also a good example for students' imitation, thus various sentences such as "My courage will go on", "My perseverance will go on", "My confidence will go on" and "My toughness will go on" can be made by students. In fact, these classical sentences, which have been in people's mind for such a long period of time, are certainly strong memes with substantially powerful longevity, thus sentences made based on these memes can effectively stimulate students' interest and frequently used by them. In this way, students are apt to make more idiomatic sentences and subsequently improve their writing.

\section{Conclusion}

With the thorough implementation of "The Belt and Road" policy and the trend of Globalization, English teaching and learning become more and more popular in primary schools in China. Furthermore, English teaching in primary school is very important in the whole process of elementary education, in which sentence imitation is regarded as a basis in second language (English) acquisition. If the teacher can effectively make full use of the three features of strong memes and consciously lead students to find out, to sum up and to make full use of strong sentence memes, students' writing ability as well as observation ability and inductive ability must be greatly improved. 


\section{References}

Chen, B., \& Zhou, L. (2015). On the Application of the Process-Oriented Writing in English Teaching in Primary Schools - A Case Study of Sentence Pattern Imitation. Education and Teaching Research, 7, 98-109.

Chen, L. (2014). English (Grade Five B). Beijing: Foreign Language Teaching and Research Press.

Chen, L. (2014). English(Grade Six A). Beijing: Foreign Language Teaching and Research Press.

Chesterman, A. (2012). The Spread of Ideas in Translation Theory. Shanghai: Shanghai Foreign Language Education Press.

Dawkins, R. (1976). The Selfish Gene. New York: Oxford University Press.

He, Z., Xie, C., \& Chen, X. (2007). New Developments in Pragmatics: Relevance, Adaptation and Memetics. Shanghai: Shanghai Education Publishing House.

Ma, X. (2014). An Inspiration of Memetics on College English Teaching of Imitation. Journal of Liaoning University of Technology (Social Science Edition), 6, 112-116.

Ministry of Education P. R. C. (2012). Compulsory Education English Curriculum Standards. Beijing: Beijing Normal University Publishing Group.

Shen, Y., \& Deng, Y. (2013). An Empirical Study on the Teaching Mode of Memetics-based "Recitaion-Imitaion-Innovation" College English Writing. Journal of Leshan Normal University, 10, $135-140$.

Wu, S. (2007). Meme and College English Teaching of Writing. Journal of Hotan Teachers College, 4, 108-110.

Xi, J. (2014). The Teaching Mode of English Writing in Vocational Colleges Based on Language Meme. Journal of Mudanjiang College of Education, 6, 76-77.

Zhang, L. (2012). The Teaching of English Writing in Vocational Colleges in Memetics Perspective. Journal of Hebei Radio \& TV University, 2, 91-93.

\section{Copyrights}

Copyright for this article is retained by the author(s), with first publication rights granted to the journal.

This is an open-access article distributed under the terms and conditions of the Creative Commons Attribution license (http://creativecommons.org/licenses/by/4.0/). 